\title{
A New Comprehensive Evaluation on Engineering Student Achievement
}

\author{
Hongying Sun ${ }^{1, a}$, Caiping Xia ${ }^{1, b}$, Jinfeng Dong ${ }^{1, c}$ \\ ${ }^{1}$ College of Engineering and Technology, Tianjin Agricultural University,Tianjin,300384,China

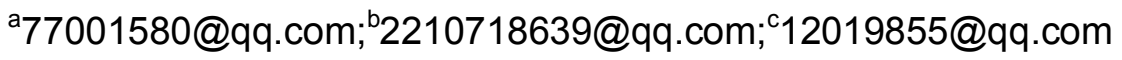

\begin{abstract}
Keywords: Grade point; Z score method; Course importance coefficient; Performance evaluation Abstract. In Tianjin Agriculture University agricultural student achievement is generally higher than that of engineering student's because of the difference of different professions, i.e. agricultural course are much easier to master relative to engineering courses and that lead to unfair assessment and appraisal of student achievement. Therefore, a new comprehensive evaluation on student achievement based on standardized achievement ratio remains unchanged and average standardized scores unchanged between different courses which make the comparison of student of different major possible is presented in this paper.
\end{abstract}

\section{Introduction}

Nowadays, credit system is widely used in colleges and universities, where each course is assigned a credit rating reflecting the number of weekly contact hours and cumulative grade point average is used to evaluate student achievement. The main components of the credit system are elective courses, credits and grade point ${ }^{[1]}$ 。 How to make the implement of credit system in colleges and universities more reasonable and convenient and for the justice and convenience of management of colleges and universities is the key problem in our research. In this paper, the mathematic model of credit system under the credit grade point was discussed and a new comprehensive evaluation on student achievement which make the comparison of student of different major more reasonable and convenient is presented in this paper.

\section{The research status at home and abroad}

2.1 In the United States, the method to calculate GPA is to calculate the sum of the producet course grade and credits, and the sum is then divided by total credit. As shown in Table 1:

Table 1

\begin{tabular}{|c|c|c|c|c|c|}
\hline level & A & B & C & D & F \\
\hline credits & 4.0 & 3.0 & 2.0 & 1.0 & 0 \\
\hline score & $100 \sim 90$ & $89 \sim 80$ & $79 \sim 70$ & $69 \sim 60$ & $59 \sim 0$ \\
\hline
\end{tabular}

For example, a student's four course credits and grades: a course 6 points, scores 90;b course 4 points, scores 88 ;c course 1 points, scores 65 and d course 3 points, scores 78 ; The student's GPA is as follows: $[(4 * 6)+(3 * 4)+(1 * 1)+(2 * 3)] /(6+4+1+3)=3.07$

2.2 In China, the calculation of GPA has the following several ways:

2.2.1 Introduced a concept of course importance coefficient. For example, the main basic course 1.2 and the other course 1.00. If use course importance coefficient, involve the issue of how to determine the course importance coefficient,some documents mentioned with deviation or biggest objective evaluation such as principal component analysis (pca) method to determine the course importance coefficient.According to the differences between students' scores of empowerment approach,the purpose is to make the weighted results discrete degree is the largest,But, in fact, this method without strict mathematical proof, obviously is not correct.

2.2.2 The average credit grade point method.With the sum of all the courses for credit grade point, divided by the total number of credits, we can get it.Two different schools, for example, A and B, The difficulty of the schools A harder than B,the result is A school students average credit grade point under school B.But it doesn't prove that schools A students ability is lower thanB. 


\section{The score standardization principles and methods}

\section{Principle}

Suppose $\mathrm{N}$ students take $\mathrm{M}$ course examination, the first of $\mathrm{i}$ student the raw score is $\mathrm{j}$ course $f_{i j}$, standardized scores for $F_{i j}$, one of them $i \in\{1,2, \ldots, N\}, j \in\{1,2, \ldots, M\}$.

The original student score data contains two pieces of information:Different students of high and low score difference information and the degree of relationship between students' scores of relevant information. Student achievement for related performance, if questions simple student performance as a whole is on the high side, will and vice versa.

Standardization method, we think, should not change the information contained in the original scores, and standardized achievement on the amount of data must be comparable, otherwise unable to comprehensive evaluation. Therefore, standardized method is put forward two principles:

3.1.1Standardized scores proportion each other the same principle

$$
\frac{f_{k j}}{f_{l j}}=\frac{F_{k j}}{F_{l j}}
$$

$f_{k j}$ and $f_{l j}$ Respectively for the students $k$ and students $l_{\text {get raw score is the first course }} f_{i j}, F_{k j}$ and $F_{l j}$ is a standardized scores.

The standardization of the course grades mean equal principle, that for the course $p, q \in\{1,2, \ldots, M\}$ $\frac{1}{N} \sum_{i=1}^{N} F_{i p}=\frac{1}{N} \sum_{i=1}^{N} F_{i q}$

Mean equal principle is, in fact, make different course is the same or different school grades comparable.

Such as two different professional Z1 and Z2, courses that difference is very big, professional Z1 item difficulty generally low, professional $Z 2$ item difficulty generally on the high side, if the current grade point average credit evaluation, will draw a professional Z1 students professional Z2 is generally good.

If be standardized in accordance with the principle of equal average students scores, can very good solution to this problem.

\section{The problems existing in the $Z$ score method}

$\mathrm{Z}$ score is now more commonly used method of standardization

$$
F_{i j}=\left(f_{i j}-\bar{f}_{j}\right) / s_{j}
$$

The average $\bar{f}_{j}=\frac{1}{N} \sum_{i=1}^{N} f_{i j}$

The standard deviation $s_{j}=\left[\frac{1}{N-1} \sum_{i=1}^{N}\left(f_{i j}-\bar{f}_{j}\right)^{2}\right]^{\frac{1}{2}}$

$\mathrm{Z}$ score can dilute the original score absoluteness, can reflect the examinee in the relative position of all candidates groups, in addition to the item difficulty different effects, make different professional school students in different grades have the comparability (average 0), but lack the information to different students of high and low score difference, in violation of the principle of standardized scores after mutual ratio unchanged. 
Table 2: Raw score of students

\begin{tabular}{|c|c|c|c|c|}
\hline results & student 1 & student 2 & student 3 & student 4 \\
\hline course 1 & 90 & 91 & 90 & 89 \\
\hline course 2 & 80 & 60 & 80 & 100 \\
\hline
\end{tabular}

Raw score of students is shown in Table 2, according to the $\mathrm{Z}$ score is shown in Table 3 :

Table 3: Students of Z score

\begin{tabular}{|c|c|c|c|c|}
\hline results & student 1 & student 2 & student 3 & student 4 \\
\hline course 1 & 0 & 1.2 & 0 & -1.2 \\
\hline course 2 & 0 & -1.2 & 0 & 1.2 \\
\hline
\end{tabular}

It can be seen that the four students on the degree of master course 1 is almost no difference, but on the degree of master course 2 have obvious differences, students 4 is clearly the best, but it can't do this kind of method of standard score difference, root cause is the standard score method lost information, differences between students of high and low scores also violates the principle of standardized scores after mutual ratio unchanged.

When the exam of degree of differentiation is not at the same time.In fact, many schools, many teachers can't be in the title will they draw all of the questions the degree of differentiation are doing exactly the same, and is also the biggest $\mathrm{Z}$ score method.

\section{Average method}

sing the average method to standardize students scores, can make the results comparable, and kept the primitive score differences between the students information, we introduce the using the average method to standardize the raw score of the student $F_{i j}=f_{i j} / \bar{f}_{j}$

After using the average method to strictly comply with the standardized scores proportion each other the same principles and the standardization of the course grade average equal principle, by using the average method to deal with the table 1 score, as shown in Table 4.

Table 4: The students' standard grades

\begin{tabular}{|c|c|c|c|c|}
\hline results & student 1 & student 2 & student 3 & student 4 \\
\hline course 1 & 1 & 1.01 & 1 & 0.99 \\
\hline course 2 & 1 & 0.75 & 1 & 1.25 \\
\hline
\end{tabular}

Obviously, using the average method to make class 1 and class 2 grade not only comparable equal (average), and keep the difference between student achievement information.

3.4Comprehensive evaluation method

In order to reflect the main basic course and subject backbone course is the important influence to the quality of teaching, we use performance assessment in the course of importance coefficient of this concept. The main basic course and the main disciplines: 1.2 , the other courses: 1.00 .

We recommend using the following comprehensive evaluation method:

Course grade point $=$ points $*$ importance coefficient $*$ standard grades

If we do not distinguish between course importance, can buy importance coefficient is 1 .

$$
\text { The average credit score }=\sum \text { course grade/total credit }
$$

\section{Application examples and effects}

For the same professional student achievement evaluation

In Tanjin agricultural university college of engineering 1 class A semester in the first 5 (Table 5), 
Table 5: The top ten of college of engineering and technology

\begin{tabular}{|c|c|c|c|c|}
\hline & course 1 & course 2 & course 3 & course 4 \\
\hline 1 & 95 & 70 & 96 & 94 \\
\hline 2 & 89 & 99 & 88 & 88 \\
\hline 3 & 90 & 66 & 90 & 90 \\
\hline 4 & 83 & 78 & 83 & 83 \\
\hline 5 & 92 & 56 & 92 & 92 \\
\hline
\end{tabular}

According to the $\mathrm{Z}$ score method: student 1 is the best, but course 1, 3, 4 score higher, student performance difference is not obvious. Course 2 difference is bigger; more can reflect the differences between students' test scores. Such as Z score method objective evaluation method not reflect different item difficulty leads to different degree of differentiation. If the GPA evaluation, will also come to the conclusion that students 1 is the best.

According to the average standardized method, reflect the difference between these grades, student 1 is the best.

Table 6: The top ten from college of horticulture

\begin{tabular}{|c|c|c|c|c|}
\hline & course 1 & course 2 & course 3 & course 4 \\
\hline 1 & 84 & 61 & 87 & 83 \\
\hline 2 & 79 & 89 & 78 & 78 \\
\hline 3 & 80 & 60 & 73 & 66 \\
\hline 4 & 73 & 68 & 73 & 73 \\
\hline 5 & 82 & 52 & 82 & 82 \\
\hline
\end{tabular}

4.2Between different specialty students evaluation

For example, in a class certain semesters of the top ten in Tianjin Agricultural University college of engineering and technology, and college of horticulture. Choose the best of the two students from each college. From Table 6, the college of horticulture grades generally low, If only from GPA to examine, the two students were by college of engineering and technology for sure. But if using average standardized method will choose one student from each college, conform to the actual situation of the students learning.

\section{Acknowledgements}

This research was performed with financial support from the Agricultural University Teaching Foundation of Tianjin under the project No. 201410061069, the Natural Science Foundation of Tianjin under the project No. 14JCYBJC30400 and Tianjin Education Project No. 20140621.

\section{References}

[1] Qiulan Luo,Youlu Chen.Under the credit system for credit grade point measurement model research. Mathematical statistics and management, $48-53,2004$. in Chinese 